\title{
Mechanical Properties of Al-SiC Metal Matrix Composites Fabricated by Stir Casting Route
}

\author{
Rajesh Agnihotri* and Santosh Dagar \\ University Institute of Engineering and Technology, India \\ *Corresponding author: Rajesh Agnihotri, University Institute of Engineering and Technology, India

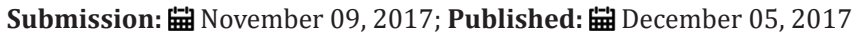

\begin{abstract}
Aluminium and its alloys possess excellent properties such as low density, good plasticity and ductility. They find extensive applications in aeronautics, astronautics, automobile and high speed train fields. The matrix alloy, the reinforcement material, the volume and shape of the reinforcement, the location of the reinforcement, and the fabrication method can all be varied to achieve required properties [1]. Metal matrix composites (MMCs), such as $\mathrm{SiC}$ particle reinforced $\mathrm{Al}$, are one of the widely known composites because of their superior properties such as high strength, hardness, stiffness, wear and corrosion resistance. SiC particle reinforced $\mathrm{Al}$ based MMCs are among the most common MMC and available ones due to their economical production [2].
\end{abstract}

\section{Introduction}

Composite materials are important engineering materials due to their outstanding mechanical properties. Composites are materials in which the desirable properties of separate materials are combined by mechanically or metallurgically binding them together. Each of the components retains its structure and characteristic, but the composite generally possesses better properties. Composite materials offer superior properties to conventional alloys for various applications as they have high stiffness, strength and wear resistance. The development of these materials started with the production of continuous-fiberreinforced composites. The high cost and difficulty of processing these composites restricted their application and led to the development of particulate reinforced composites [3,4]. Aluminium and its alloys possess excellent properties such as low density, good plasticity and ductility and good corrosion resistance. They find extensive applications in aeronautics, astronautics, and automobile and high speed train fields. However, low hardness and poor impact resistance results in their limited application in heavy duty environments. Like all composites, aluminium-matrix composites are not a single material but a family of materials whose stiffness, strength, density, thermal and electrical properties can be tailored [5]. The matrix alloy, the reinforcement material, the volume and shape of the reinforcement, the location of the reinforcement, and the fabrication method can all be varied to achieve required properties [6]. Regardless of the variations, however, $\mathrm{Al}$ composites offer excellent thermal conductivity, high shear strength, excellent abrasion resistance, high temperature operation, non-flammability, minimal attack by fuels and solvents, and the ability to be formed and treated on conventional equipment.
Silicon carbide $(\mathrm{SiC})$ is composed of tetrahedral of carbon and silicon atoms with strong bonds in the crystal lattice. This produces a very hard and strong material. $\mathrm{SiC}$ is not attacked by any acids or alkalis or molten salts up to $800{ }^{\circ} \mathrm{C}$. In air, SiC forms a protective silicon oxide coating at $1200^{\circ} \mathrm{C}$ and is able to be used up to $1600^{\circ} \mathrm{C}$. The high thermal conductivity coupled with low thermal expansion and high strength gives this material exceptional thermal shock resistant qualities. SiC ceramics with little or no grain boundary impurities maintain their strength to very high temperatures, approaching $1600^{\circ} \mathrm{C}$ with no strength loss [7].

Metal matrix composites (MMCs), such as SiC particle reinforced $\mathrm{Al}$, are one of the widely known composites because of their superior properties such as high strength, hardness, stiffness, wear and corrosion resistance. SiC particle reinforced $\mathrm{Al}$ based MMCs are among the most common MMC and available ones due to their economical production. They can be widely used in the aerospace, automobiles industry such as electronic heat sinks, automotive drive shafts, or explosion engine components.

\section{Experimental}

In this study, an attempt has been made to fabricate aluminum (Al-6061)/SiC (Silicon carbide) MMCs by STIR casting process [8]. The MMCs plates were prepared with varying the reinforced particles by weight fraction of $5 \%, 10 \%$ and $15 \%$. The average reinforced particles size of $\mathrm{SiC}$ was 325 mesh respectively. The stirring process was carried out at $200 \mathrm{rev} / \mathrm{min}$ rotating speed.

\section{Composition of samples chosen for the study}

Al-SiC composites have been prepared by varying the $\mathrm{SiC}$ 
weight percentage from 5 to $15 \%$. The weight of sample taken is 400 grams and the percentages are varied accordingly. Table 1 shows the composition of samples.

Table 1: Composition of samples.

\begin{tabular}{|c|c|c|c|}
\hline Sample No. & $\begin{array}{c}\text { Aluminium } \\
\text { (Grams) }\end{array}$ & Sic (Grams) & Remarks \\
\hline 1 & 380 & 20 & $\mathrm{Al}-5 \% \mathrm{SiC}$ \\
\hline 2 & 360 & 40 & $\mathrm{Al}-10 \% \mathrm{SiC}$ \\
\hline 3 & 340 & 60 & $\mathrm{Al}-15 \% \mathrm{SiC}$ \\
\hline
\end{tabular}

\section{Stir casting procedure for Al6061/SiC MMCs [9-11]}

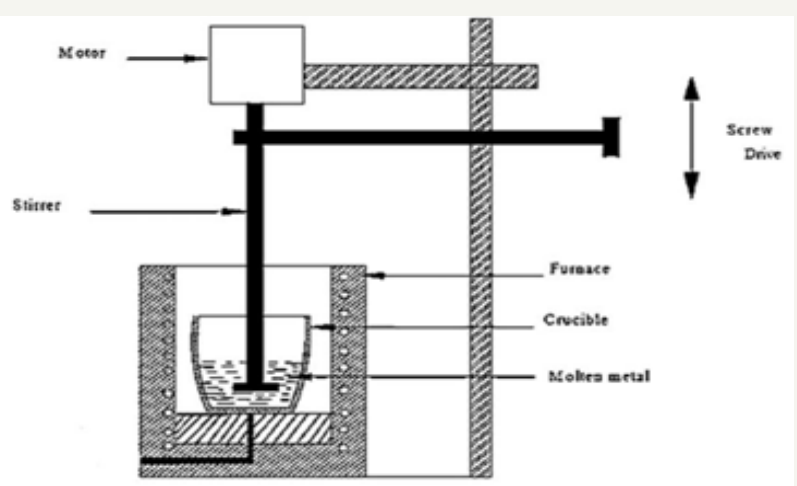

Figure 1: Stir casting setup for fabrication of $\mathrm{Al}-\mathrm{SiC}_{\mathrm{p}} \mathrm{MMC}$

The stir casting experimental setup used for fabricating Al$\mathrm{SiC}_{\mathrm{p}} \mathrm{MMC}$ is shown in Figure 1. It consists of furnace for heating the metal, Stirrer and motor for mixing of particles. First of all, the $\mathrm{SiC}$ particles are preheated in a separate muffle furnace at $900{ }^{\circ} \mathrm{C}$ for $2 \mathrm{~h}$ in order to remove the volatile substances and impurities present and to maintain the particle temperature closer to melting point of aluminium alloy. The preheating of $\mathrm{SiC}$ particles leads to the artificial oxidation of the particle surface forming $\mathrm{SiO}_{2}$ layer. This $\mathrm{SiO}_{2}$ layer helps in improving the wettability of the particle. Thereafter, Al6061 billets were charged into the furnace and melting was allowed to progress until a uniform temperature of $750{ }^{\circ} \mathrm{C}$ was attained. The flux is added to $\mathrm{Al}$ alloy during melting to prevent oxidation of the aluminium. The melt was then allowed to cool to $600{ }^{\circ} \mathrm{C}$ (slightly below the liquidus temperature) to a semisolid state and silicon carbide preheated mixture was added to the melt in fragments and manual stirring of the slurry was performed. Thereafter, small amount of Mg less than $1 \%$ of the total weight is added to improve the wettability between the reinforcement and the alloy. After performing 5 min of manual stirring, rest amount of $\mathrm{SiC}$ is added along with the hexachloroethane tablets for degassing the molten metal and to prevent porosity in the cast composites.

After the manual stirring, the composite slurry was reheated and maintained at a temperature of $750{ }^{\circ} \mathrm{C} \pm 10{ }^{\circ} \mathrm{C}$ (above the liquidus temperature) and then mechanical stirring was performed. The stirring operation was performed for 10 minutes at an average stirring rate of 150rpm. Platinum-Rhodium thermocouple was utilized in all cases to monitor the temperature readings of the furnace. The permanent cast iron mould is preheated at a temperature of $350{ }^{\circ} \mathrm{C}$ before the pouring of composite mixture in to it. After that the composite is solidified, dried and taken out from the permanent mould.

\section{Results and Discussion}

\section{Metallography and microstructural analysis}

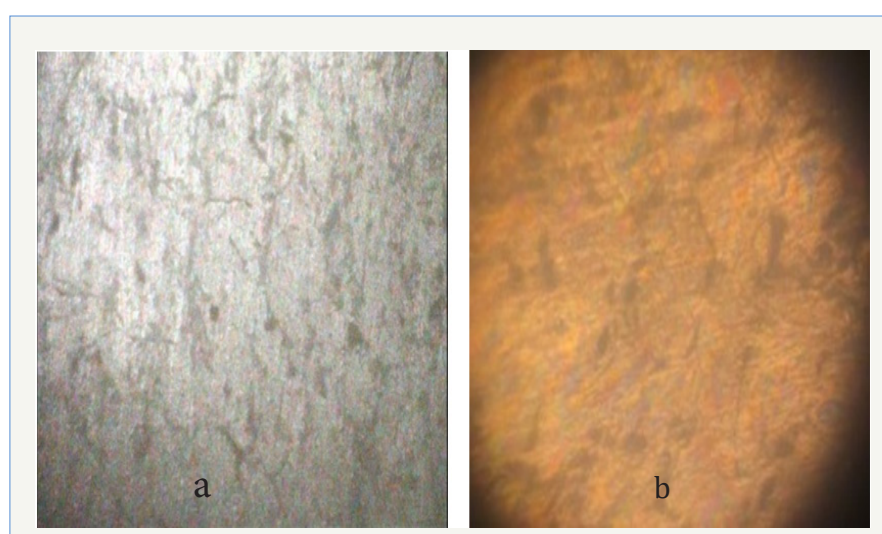

Figure 2a $\mathbf{8}$ 2b: Shows optical microstructures of Al-5\% $\mathrm{SiC}$ composite at $100 \mathrm{x}$ and $200 \mathrm{x}$ magnification respectively.
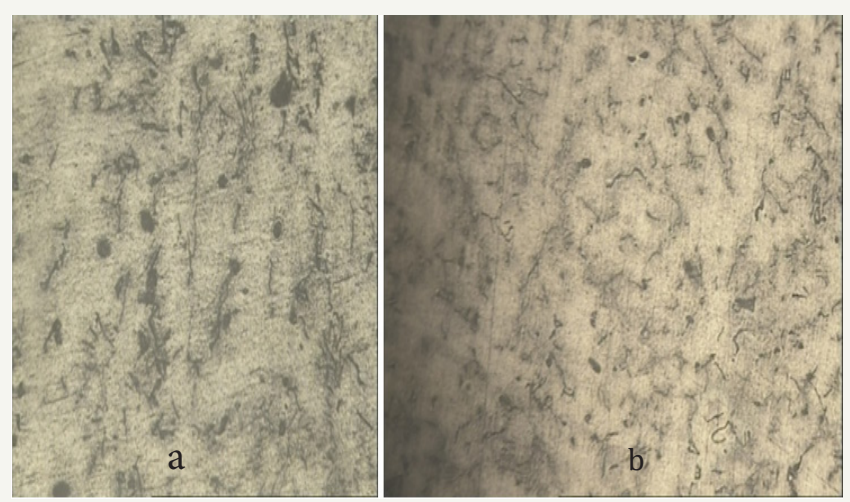

Figure 3a \& 3b: Shows optical microstructures of Al-10\% $\mathrm{SiC}$ composite at $100 \mathrm{x}$ and $200 \mathrm{x}$ magnification respectively.

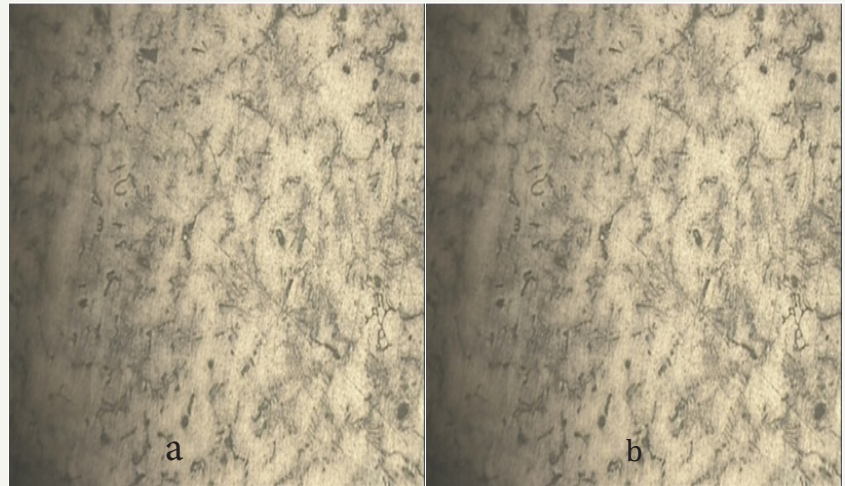

Figure 4a \& 4b: Shows optical microstructures of Al-15\% $\mathrm{SiC}$ composite at $100 \mathrm{x}$ and $200 \mathrm{x}$ magnification respectively.

Microstructural analysis: The microstructural investigation of the stir casted $\mathrm{Al} 6061 / 5 \% \mathrm{SiC}_{\mathrm{p}}, \mathrm{Al} 6061 / 10 \% \mathrm{SiC}_{\mathrm{p}}$ and Al6061/15\% $\mathrm{SiC}_{\mathrm{p}} \mathrm{MMC}$ has been carried out by optical microscope. The Optical microstructures are shown in Figure 2-4 at 100x and 
200x. The optical micrographs of the as-cast composite revealed that the agglomerations of $\mathrm{SiC}$ particles are uniformly distributed in the matrix. It is apparent from the microstructure that the distributions of reinforcement particles become more uniform in the matrix as their weight percentage increases.

\section{XRD analysis}

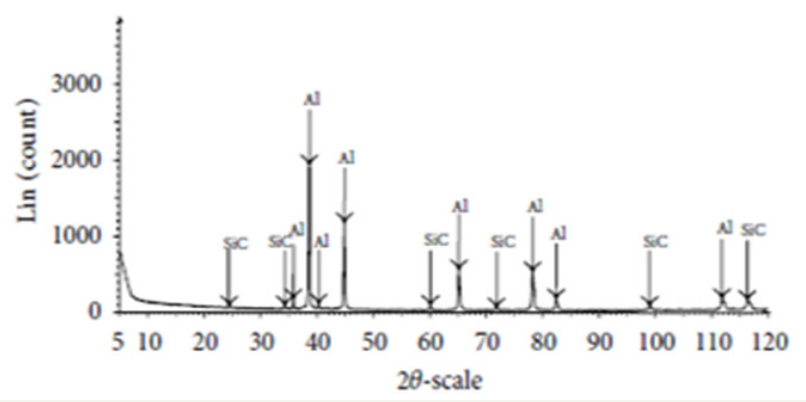

Figure 5a: $\mathrm{Al} 6061 / 5 \% \mathrm{SiC}_{\mathrm{p}}$.

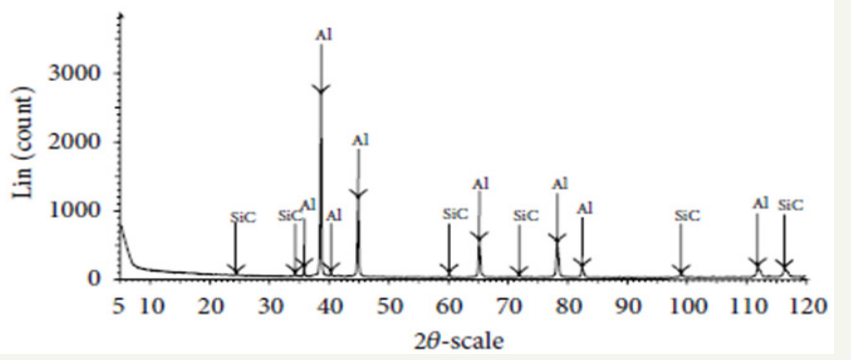

Figure 5b: $\mathrm{A} 16061 / 10 \% \mathrm{SiC}_{\mathrm{p}}$.

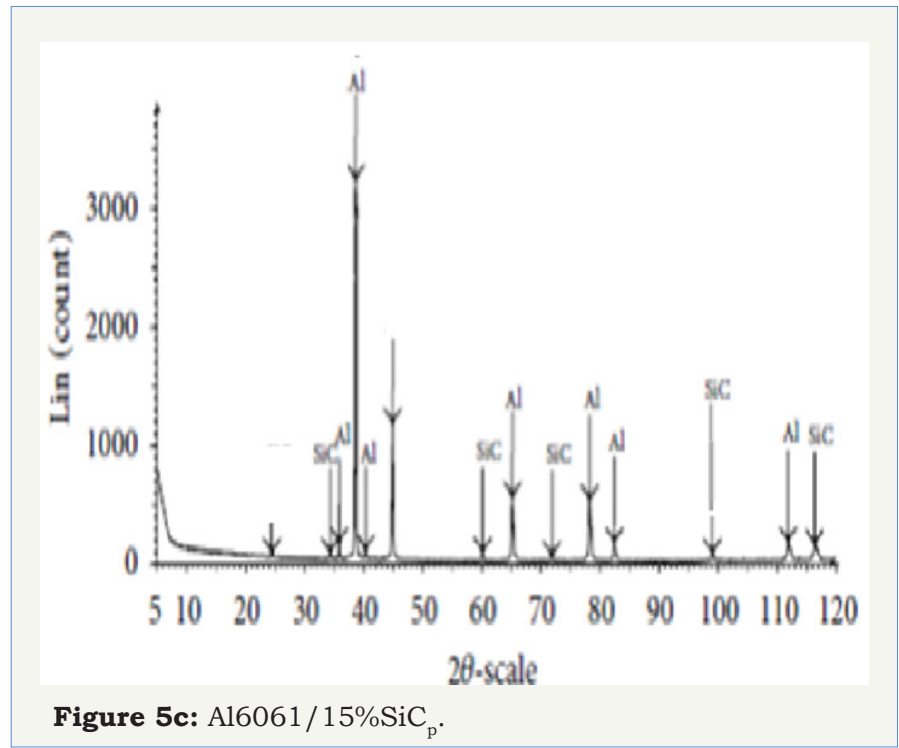

XRD analysis shows that no other unwanted materials were present instead of $\mathrm{Al}$ and $\mathrm{SiC}$. Figure $5 \mathrm{a}-5 \mathrm{c}$ shows the XRD patterns

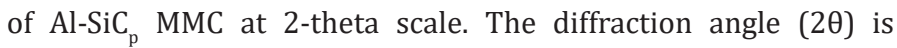
maintained between $5^{\circ}$ and $120^{\circ}$.

\section{X-Ray fluoroscence spectroscopy (XRF)}

A WD-XRF Spectrometer Model-S8, Make TIGER Bruke has been used for analyzing the elemental composition and spectrum of Al-SiC MMC. Circular samples of $34 \mathrm{~mm}$ diameter are prepared for XRF analysis. It has been concluded that the $\mathrm{SiC}$ is uniformly dispersed throughout the matrix. Moreover, compositional analysis reveals the presence of Silicon and carbon Figure 6a- $6 c$.

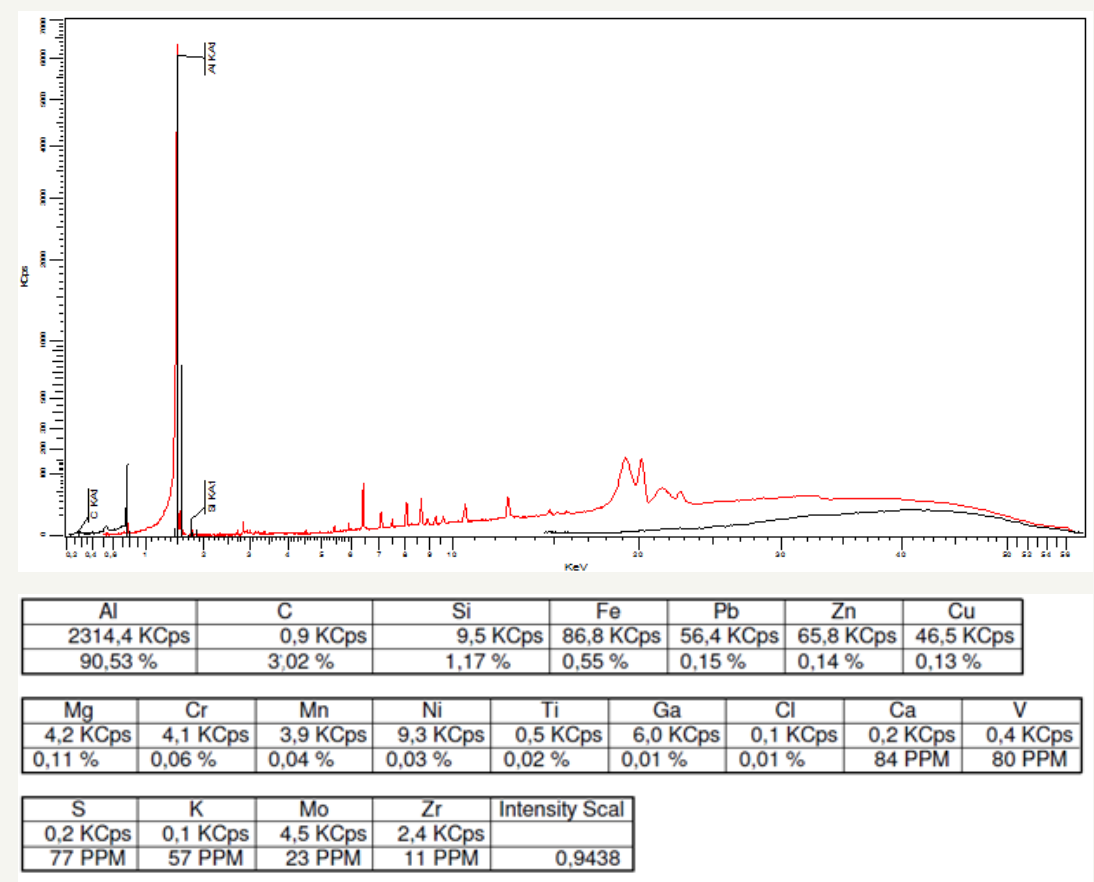

Figure 6a: XRF Spectrum and composition of $\mathrm{Al}-5 \% \mathrm{SiC}_{\mathrm{p}} \mathrm{MMC}$. 


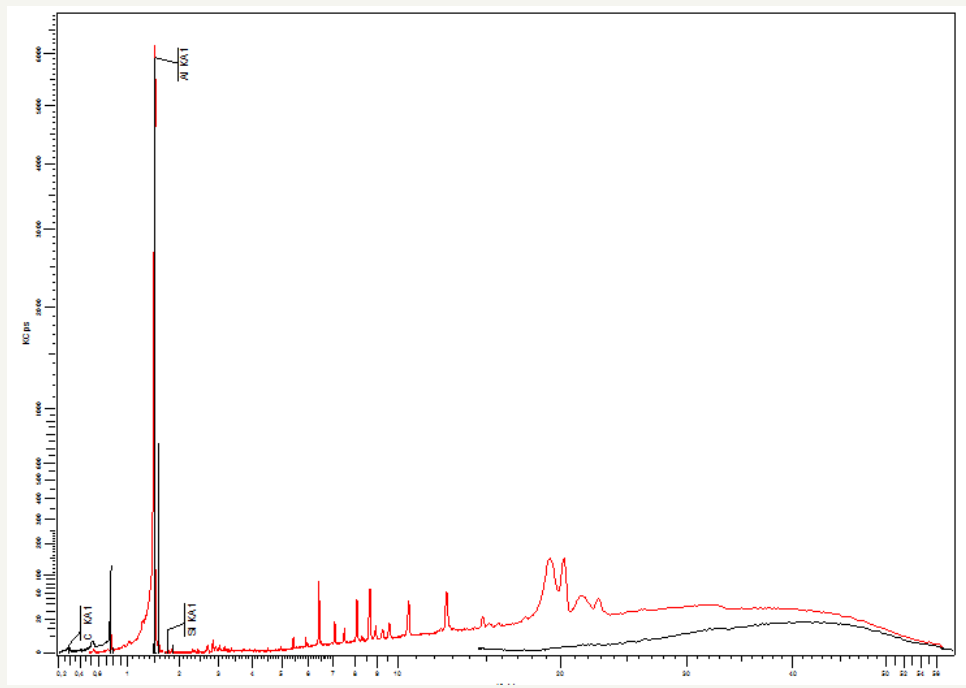

\begin{tabular}{|c|c|c|c|c|c|c|}
\hline Al & C & $\mathrm{Si}$ & $\mathrm{Fe}$ & $\mathrm{Mg}$ & $\mathrm{Zn}$ & $\mathrm{Pb}$ \\
\hline $2306,0 \mathrm{KCps}$ & $1,0 \mathrm{KCps}$ & $14,4 \mathrm{KCps}$ & $72,1 \mathrm{KCps}$ & $9,2 \mathrm{KCps}$ & $41,1 \mathrm{KCps}$ & $30,7 \mathrm{KCps}$ \\
\hline $88,90 \%$ & $8,27 \%$ & $1,73 \%$ & $0,45 \%$ & $0,24 \%$ & $0,09 \%$ & $0,08 \%$ \\
\hline
\end{tabular}

\begin{tabular}{|l|c|c|c|c|c|c|c|c|}
\hline \multicolumn{1}{c|}{$\mathrm{Cu}$} & $\mathrm{Cr}$ & $\mathrm{Mn}$ & $\mathrm{Cl}$ & $\mathrm{Ni}$ & $\mathrm{Ti}$ & $\mathrm{Ga}$ & $\mathrm{K}$ & $\mathrm{S}$ \\
\hline $27,8 \mathrm{KCps}$ & $2,6 \mathrm{KCps}$ & $3,5 \mathrm{KCps}$ & $0,3 \mathrm{KCps}$ & $6,2 \mathrm{KCps}$ & $0,4 \mathrm{KCps}$ & $5,8 \mathrm{KCps}$ & $0,2 \mathrm{KCps}$ & $0,2 \mathrm{KCps}$ \\
\hline $0,07 \%$ & $0,04 \%$ & $0,03 \%$ & $0,02 \%$ & $0,02 \%$ & $0,01 \%$ & $99 \mathrm{PPM}$ & $80 \mathrm{PPM}$ & $80 \mathrm{PPM}$ \\
\hline
\end{tabular}

\begin{tabular}{|c|c|c|c|c|r|}
\hline $\mathrm{Ca}$ & $\mathrm{Ag}$ & $\mathrm{Pd}$ & Mo & Zr & Intensity Scal \\
\hline $0,2 \mathrm{KCps}$ & $0,4 \mathrm{KCps}$ & $0,3 \mathrm{KCps}$ & $3,2 \mathrm{KCps}$ & $2,3 \mathrm{KCps}$ & \\
\hline $75 \mathrm{PPM}$ & $55 \mathrm{PPM}$ & $39 \mathrm{PPM}$ & $15 \mathrm{PPM}$ & $11 \mathrm{PPM}$ & 0,9370 \\
\hline
\end{tabular}

Figure 6b: XRF Spectrum and composition of $\mathrm{Al}-10 \% \mathrm{SiC}_{\mathrm{p}} \mathrm{MMC}$.

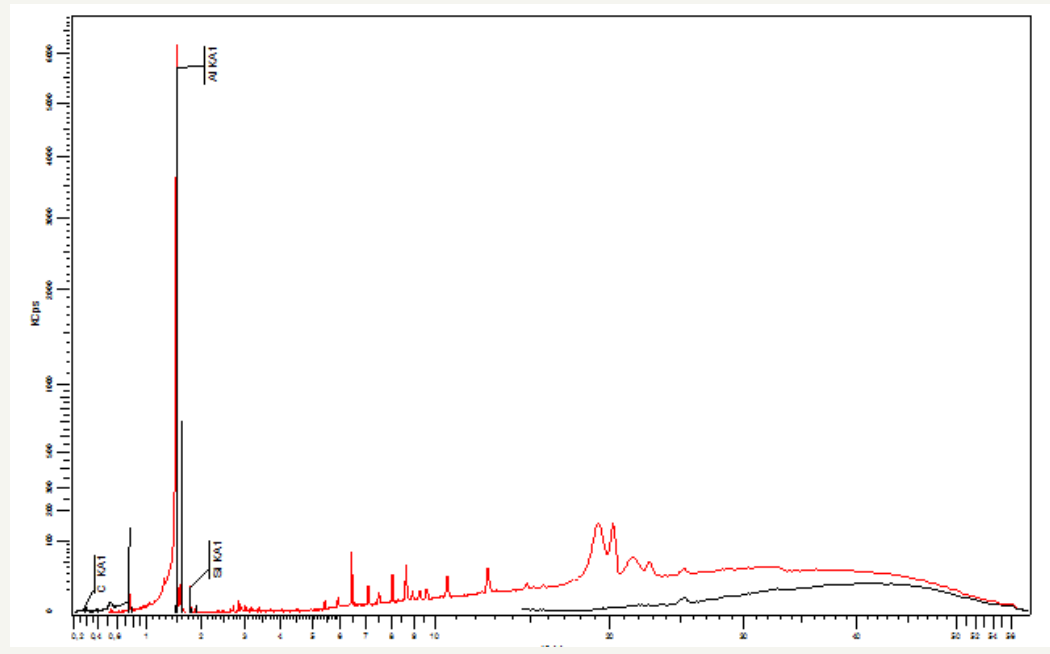

\begin{tabular}{|c|c|c|c|c|c|c|}
\hline Al & C & Si & Fe & \multicolumn{1}{c|}{$\mathrm{Pb}$} & \multicolumn{1}{c|}{ Zn } & Cu \\
\hline $2366,2 \mathrm{KCps}$ & $0,8 \mathrm{KCps}$ & $7,9 \mathrm{KCps}$ & $71,8 \mathrm{KCps}$ & $30,5 \mathrm{KCps}$ & $35,0 \mathrm{KCps}$ & $26,3 \mathrm{KCps}$ \\
\hline $91,42 \%$ & $6,78 \%$ & $5,98 \%$ & $0,46 \%$ & $0,08 \%$ & $0,07 \%$ & $0,07 \%$ \\
\hline
\end{tabular}

\begin{tabular}{|c|c|c|c|c|c|c|c|c|}
\hline $\mathrm{Cr}$ & $\mathrm{Mn}$ & $\mathrm{Ni}$ & $\mathrm{Ti}$ & $\mathrm{Ga}$ & $\mathrm{Cl}$ & $\mathrm{V}$ & $\mathrm{Ca}$ & $\mathrm{S}$ \\
\hline $2,4 \mathrm{KCps}$ & $3,3 \mathrm{KCps}$ & $5,4 \mathrm{KCps}$ & $0,6 \mathrm{KCps}$ & $5,8 \mathrm{KCps}$ & $0,1 \mathrm{KCps}$ & $0,3 \mathrm{KCps}$ & $0,1 \mathrm{KCps}$ & $0,1 \mathrm{KCps}$ \\
\hline $0,03 \%$ & $0,03 \%$ & $0,02 \%$ & $0,02 \%$ & $0,01 \%$ & $70 \mathrm{PPM}$ & $66 \mathrm{PPM}$ & $56 \mathrm{PPM}$ & $55 \mathrm{PPM}$ \\
\hline
\end{tabular}

\begin{tabular}{|c|c|r|}
\hline Mo & \multicolumn{1}{|c|}{$\mathrm{Zr}_{\mathrm{r}}$} & Intensity Scal \\
\hline $2,8 \mathrm{KCpS}$ & $2,5 \mathrm{KCps}$ & \\
\hline $13 \mathrm{PPM}$ & $12 \mathrm{PPM}$ & 0,9446 \\
\hline
\end{tabular}

Figure 6c: XRF Spectrum of $\mathrm{Al}-15 \% \mathrm{SiC}_{\mathrm{p}} \mathrm{MMC}$. 


\section{Hardness testing}

The resistance to indentation or scratch is termed as hardness. Among various instruments for measurement of hardness, Brinell's, Rockwell's and Vicker's hardness testers are significant. Vickers hardness value of Al-SiC MMCs taken at $10 \mathrm{Kgf} \mathrm{load}$ and $10 \mathrm{sec}$ dwell time using micro indenter of diamond is shown in Table 2 and also in Figure $7 \& 8$.

Table 2: Vickers Hardness value of Al-SiC MMCs.

\begin{tabular}{|c|c|c|}
\hline S. No. & Samples & Hardness (HV10) \\
\hline 1 & Al- $5 \% \mathrm{SiC}$ & 36 \\
\hline 2 & Al- $10 \% \mathrm{SiC}$ & 45 \\
\hline 3 & Al- $15 \% \mathrm{SiC}$ & 50 \\
\hline
\end{tabular}

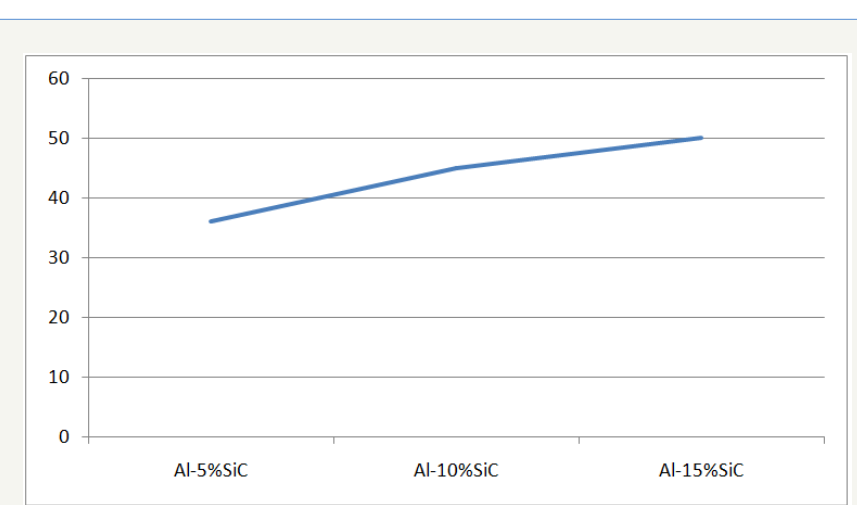

Figure 7: Shows the graph between hardness value and percentage of $\mathrm{SiC}$..

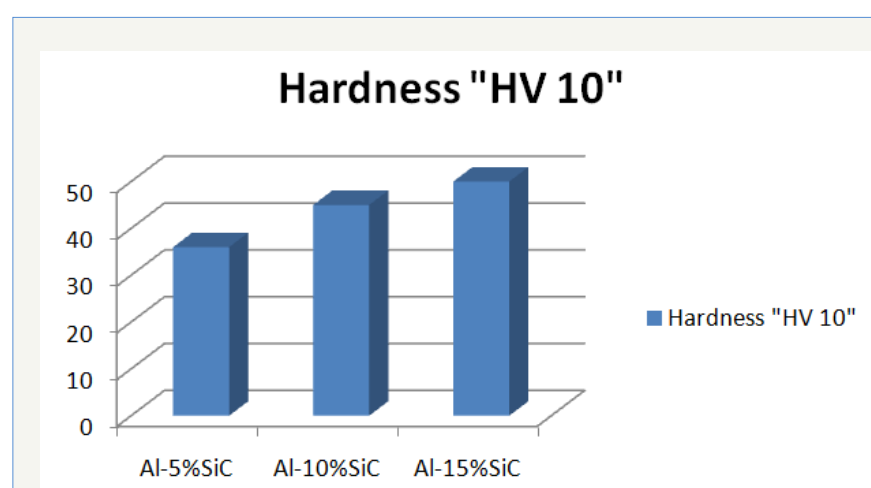

Figure 8: Shows the bar chart diagram which representing the trends in increasing hardness on increment of $\mathrm{SiC}$ content.

\section{Wear testing}

Wear resistance testing was done on Pin-On-Disc machine at load of $15 \mathrm{~N}$ and rotational speed of disc of 400rpm. Standard cylindrical pin wear testing sample was prepared on the lathe machine having dimensions of $8 \mathrm{~mm}$ diameter and 1inch length as shown in Figure 9.

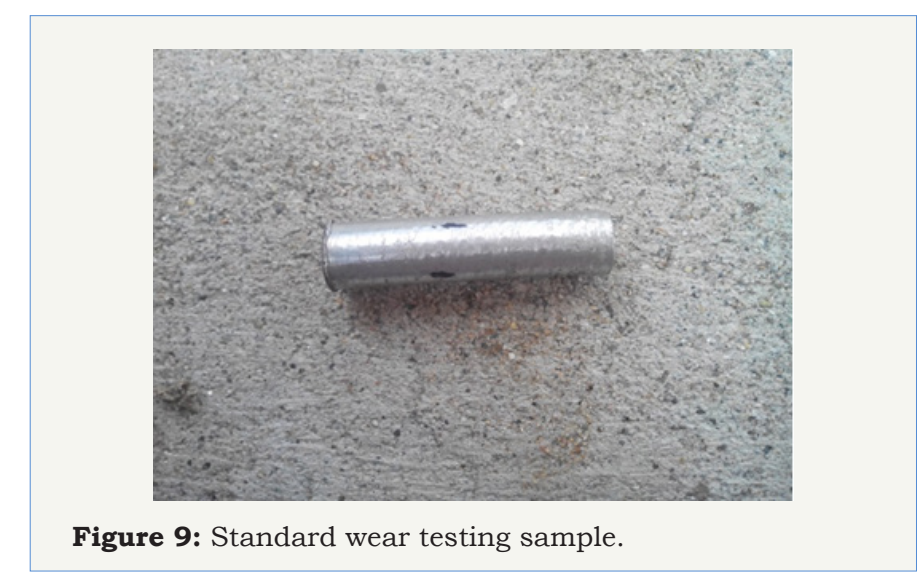

\section{Wear testing parameters}

Following parameters were used to perform wear test:

Load (N)-15 Newton, Disk Rotation speed-400rpm.

Track radius- $60 \mathrm{~mm}$, Time- 60 minutes

Wear testing results of Al-SiC MMCs on pin-on-disc setup at $15 \mathrm{~N}$ load and 400rpm speed are shown in Table 3 and Figure 10 giving the trends in wear resistance value on increment in SiC content

Table 3: Wear Rate of Al-SiC MMCs.

\begin{tabular}{|c|c|}
\hline $\begin{array}{c}\text { Al- SiC Composites of Varying } \\
\text { Amounts of SiC }\end{array}$ & Wear Rate $\left(\mathbf{M m}^{\mathbf{3}} \mathbf{\mathbf { M } )}\right.$ \\
\hline Al base alloy & 0.832475 \\
\hline Al-5\% SiC Composites & 0.732448 \\
\hline Al-10\% SiC Composites & 0.632448 \\
\hline Al-15\% SiC Composites & 0.405977 \\
\hline
\end{tabular}

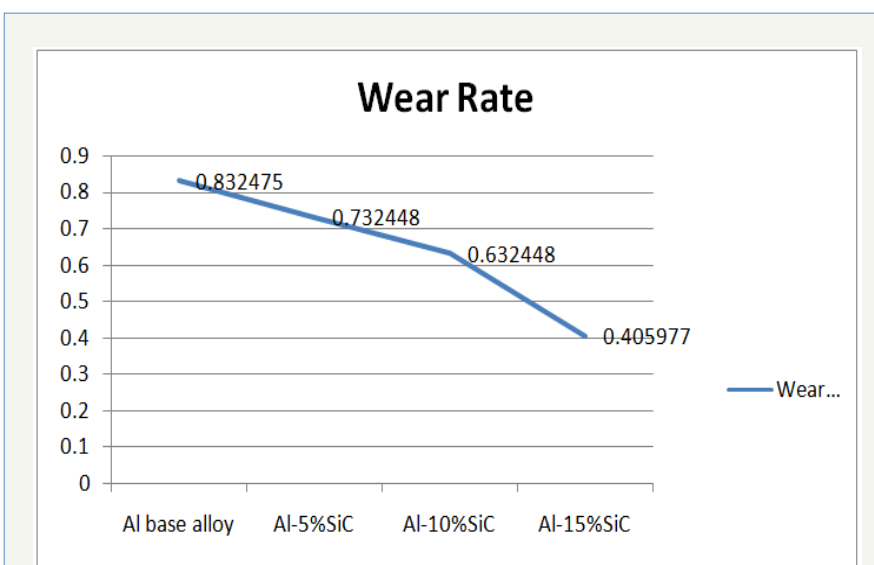

Figure 10: Shows the graph between wear resistance and percentage of $\mathrm{SiC}$ thus giving the trends in wear resistance value on increment in $\mathrm{SiC}$ content.

A. The dry sliding wear behaviour in the base alloy and composites were investigated against emery papers of 400 grit. The $\mathrm{SiC}$ particulate phase is found to reduce the wear rate (expressed in terms of $\mathrm{gm} / \mathrm{m}, \mathrm{mm}^{3} / \mathrm{m}$ etc) significantly in the composites. The volumetric wear rate $\left(\mathrm{mm}^{3} / \mathrm{m}\right)$ in $15 \% \mathrm{SiC}$ composite is reduced 
by $62-66 \%$ for 400 emery sliding with respect to the base alloy. In case of $5 \% \mathrm{SiC}$ composite the corresponding reduction in the wear rate is $15-25 \%$.

B. The wear rate is found to increase with load in all the materials studied. The increase in wear rate with load is steeper in the base alloy as compared to that of the composites. The increasing load is known to produce heating effect leading to thermal softening and seizure. Also it brings more area into sliding contact and thereby causes enhanced wear.

C. The micro mechanism of wear against the coarse abrasive emery paper was found to be characterized by deep wear tracks along with fragmented SiC particulates in the 5\% SiC composite. Fine cracks were also noticed. In $15 \% \mathrm{SiC}$ composite wear was followed by limited extent of cutting and plowing marks keeping the overall surface smooth.

\section{Tensile testing}

Table 4: Tensile Strength of Al-SiC MMCs.

\begin{tabular}{|c|c|c|c|}
\hline Samples & \%Elongation & 0.2\% Y.S(Mpa) & UTS(Mpa) \\
\hline Al6061 -5\% $\mathrm{SiC}_{\mathrm{p}}$ & 1.9 & 54.6 & 52.2 \\
\hline $\mathrm{Al} 6061-10 \% \mathrm{SiC}_{\mathrm{p}}$ & 1.3 & 42 & 39.1 \\
\hline $\mathrm{Al} 6061-15 \% \mathrm{SiC}_{\mathrm{p}}$ & 0.6 & 51 & 55.8 \\
\hline
\end{tabular}

Tensile testing was carried on Universal testing machine and the results are as under: Table 4 shows the \% elongation, yield strength at $0.2 \%$ and UTS of Al6061 $-5 \% \mathrm{SiC}_{\mathrm{p}}, \mathrm{Al} 6061-10 \% \mathrm{SiC}_{\mathrm{p}}$ and $\mathrm{Al} 6061-10 \% \mathrm{SiCp}$. It has been concluded that the \% elongation decreases with increase in $\mathrm{SiC}$ percentage. But yield strength and UTS decreases up to $10 \% \mathrm{SiC}$ and then increases.

\section{Conclusion}

Al-SiC MMC have been successfully fabricated by Stir casting. Stirring the MMC slurry in semi-solid state helps to incorporate ceramic particles into the alloy matrix. The settling of silicon carbide particles resisted due to stirring in semisolid state due to entrapment of silicon carbide particles between the dendrite arms. Processing variables such as holding temperature, stirring speed, size of the impeller, and the position of the impeller in the melt are among the important factors to be considered in the production of cast metal matrix composites as these have an impact on mechanical properties. The microstructural investigation and
XRD results reveal the uniform distribution of $\mathrm{SiC}$ particles in to Al matrix. Whereas, XRF tells us the chemical composition and spectrum of fabricated MMCs. It is very difficult to obtain the exact percentage of $\mathrm{SiC}$, but it has been successfully achieved by adopting suitable process parameters. The testing of composites have been carried out several times by XRF and then accordingly parameters are varied to achieve the homogeneous and uniform distribution of reinforcement. The addition of silicon carbide particles to the matrix alloy improves the mechanical properties such as hardness and tensile strength of the matrix alloy. But the wear rate tends to decrease with increasing particles wt. percentage from 5 to $15 \%$, which confirms that silicon carbide is beneficial for reducing the wear rate of MMCs. This material can be used at high elevated temperature stability. It can also be used for Better wear resistance, corrosion resistance.

\section{References}

1. Hashim J, Looney L, Hashmi MSJ (1999) Metal matrix composites: production by the stir casting method. Journal of Materials Processing Technology 92-93: 1-7.

2. Sarkar smarajit (2010) Some studies on aluminium matrix in-situ composites produced by chemical reaction.

3. Miracle DB, Donaldson SL (2001) Introduction to Composites. ASM Hand Book of Composite Materials, p. 21.

4. Kakani SL, Kakani A (2004) Material science. New age international publishers, India, pp. 593-613.

5. Martin JW (2006) Materials for Engineering. ( $3^{\text {rd }}$ edn), Wood Head Publishing Limited, England, pp. 1-256.

6. Dmitri Kopeliovich (2010) State fabrication of metal matrix composites.

7. Aikin RM (1997) The Mechanical Properties of In-Situ Composites, JOMa publication of The Minerals. Metals \& Materials Society 49(8): 35-39.

8. Rohatgi PK, Pasciak K, Narendranath CS, Roy S, Sachdev A, et al. (1994) J Mater Sci 29.

9. Meena KL, Manna A, Banwait SS, Jaswanti (2003) An analysis of mechanical properties of the developed $\mathrm{Al} / \mathrm{SiC}$ mmc. American journal of Mechanicla engineering 1(1): 14-19.

10. Balasivanandha PS, Karunamoorthy L, Kathiresan S, Mohan B (2006) Influence of stirring speed and stirring time on distribution of particles in cast metal matrix composite. Journal of Materials Processing Technology 171(2): 268-273.

11. Singla M, Deepak DD, Singh L, Chawla V (2009) Development of Aluminium Based Silicon Carbide Particulate Metal Matrix Composite. Journal of Minerals \& Materials Characterization \& Engineering 8(6): 455-467. 